\title{
Spectrum and features of congenital heart disease in Xi'an, China as detected using fetal echocardiography
}

\author{
Y.J. Wei ${ }^{1}$, B.M. Liu ${ }^{1}$, Y.H. Zhou ${ }^{1}$, X.H. Jia ${ }^{1}$, S.G. Mu ${ }^{2}$, X.R. Gao ${ }^{2}$, \\ M.L. Yang ${ }^{2}$ and Y. Zhang ${ }^{2}$ \\ ${ }^{1}$ Department of Ultrasonography, The Second Affiliated Hospital, \\ Xi'an Jiaotong University, Xi'an, China \\ ${ }^{2}$ Department of Ultrasonography, \\ Maternal and Child Health Hospital of Shaanxi Province, Xi'an, China \\ Corresponding author: B.M. Liu \\ E-mail: BaominLiucn@126.com
}

Genet. Mol. Res. 13 (4): 9412-9420 (2014)

Received August 9, 2013

Accepted September 11, 2014

Published November 11, 2014

DOI http://dx.doi.org/10.4238/2014.November.11.6

\begin{abstract}
This study aimed to investigate the spectrum and features of congenital heart disease (CHD) in Xi'an, China using fetal echocardiography. All pregnant women referred for fetal echocardiography underwent a systematic fetal echocardiographic examination. Each case of complex defects was diagnosed according to the predominant pathophysiology, and the overall frequency of each defect was recorded and classified according to its location in the fetal heart. CHD was diagnosed in 195 fetuses. The top 5 types of CHD were, in order, single ventricle $(15.9 \%, 31 / 195)$, atrioventricular septal defect $(12.3 \%, 24 / 195)$, ventricular septal defect (VSD) $(11.8 \%, 23 / 195)$, tetralogy of Fallot $(10.8 \%, 21 / 195)$, and double-outlet right ventricle $(8.2 \%, 16 / 195)$. The 195 cases of CHD comprised 316 defects in total. The most common defect was ventricular malformation $(40.5 \%$, 128/316), followed by great artery anomalies (38.0\%, 120/316), endocardial cushion abnormalities $(11.7 \%, 37 / 316)$, atrial abnormalities
\end{abstract}


$(6.6 \%, 21 / 316)$, and semilunar valve abnormalities (3.2\%, 10/316). VSD accounted for the largest proportion $(24.4 \%, 77 / 316)$ of the ventricular malformations. The total proportion of obstructive lesions in this group was much higher for the right than for the left side of the heart $(18.4 \%$ (58/316) vs 9.5\% (30/316), respectively). The spectrum of fetal CHD detected by echocardiography was much different compared to that accepted in the past. Complex defects were more common prenatally. Ventricular malformations were the largest constituent of all of the defects associated with fetal CHD, and VSD was the most common component of complex defects. Chinese fetal CHD encompassed more right-sided than left-sided obstructive lesions.

Key words: Fetal echocardiography; Spectrum; Congenital heart disease

\section{INTRODUCTION}

Congenital Heart Disease (CHD) refers collectively to gross structural abnormalities of the heart or intrathoracic great vessels that are of potential or actual functional significance (Mitchell et al., 1971). The incidence of CHD is generally stated to be 8-10 per 1000 live births. In the past, data concerning the incidence of each type of CHD came largely from hospital-based study cohorts, and the results of such surveys consistently indicate that the 3 most common types of CHD are ventricular septal defect (VSD), atrial septal defect (ASD), and patent ductus arteriosus (PDA), followed by complex forms of CHD (Wu et al., 2010; van der Linde et al., 2011). Several studies (Allan et al., 1985, 1994; Hsiao et al., 2007) have indicated that the spectrum of CHD differs greatly between fetuses and live-born infants. However, it is still difficult to ascertain the precise distribution of the types of CHD during the fetal period; this is especially true for the complex forms of CHD that might cause early neonatal mortality, for which studies of live-born infants could thus lead to considerable underestimation of their fetal incidence. Advances in prenatal ultrasonographic screening techniques as well as the use of fetal echocardiography have greatly improved the diagnostic accuracy of fetal CHD in recent years, and this has greatly increased the accuracy of estimations of the prevalence of CHD during the fetal period. In the present study, we performed systematic echocardiographic examination including 10 sections of the fetal heart in 4370 pregnant women who were referred for fetal echocardiography because of various high-risk traits and diagnosed a total of 195 cases of fetal CHD. The purpose of our study was to investigate the spectrum and features of fetal CHD in Xi'an, China using echocardiography.

\section{MATERIAL AND METHODS}

\section{Cases}

The study was conducted from March 2008 to July 2012 at the Second Affiliated Hospital of Xi'an Jiaotong University and the Maternal and Child Health Hospital of Shaanxi Province. All women aged 18 to 43 years (mean, 26 years) with high-risk pregnancies who 
were referred for fetal echocardiography during the study period $(\mathrm{N}=4370)$ were enrolled retrospectively in this study. The gestational age at the time of the examination was between 18 and 40 weeks in all cases. This study was conducted in accordance with the Declaration of Helsinki and with the approval of the Ethics Committee of Xi' an Jiaotong University. Written informed consent to participate was obtained from all participants. The risk factors included family history of CHD, maternal age older than 35 years, concomitant maternal disease (e.g., diabetes mellitus or collagen vascular disease), exposure to teratogens or rubella infection, and chromosomal abnormalities. Cases in which routine prenatal ultrasound screening showed an abnormal 4-chamber view, abnormal heart rhythm, or certain extracardiac abnormalities were also included.

\section{Apparatus and methods}

All of the examinations were performed by experienced investigators who had undergone uniform training and had completed $>200$ systematic echocardiography examinations. All cases of suspected CHD were confirmed by a senior cardiologist. The ultrasound machines used were the GE Vivid 7 (New York, USA), the Philips IE33 (Ende Huo Fen City, Holland), and the HD15 (Ende Huo Fen City, Holland). The transducer frequency used was 2.5-5.0 $\mathrm{MHz}$, and the fetal heart preset was selected.

All of the pregnant women laid in the supine position for the examination. A systematic examination, including 10 consecutive sections of the fetal heart, was performed as follows. 1) The fetal position was determined according to the position of the head and spine of the fetus. 2) Five transverse views were obtained following the method of Yagel et al. (2001). The first view was a transverse plane through the upper abdomen. In this view, the liver and inferior vena cava were located to the right and the stomach and aorta to the left of the spine. The second was the 4-chamber view, which showed the right and left ventricles and atria, the ventricular septum, the atrial septum, and the foramen ovale; this is the most important view for fetal echocardiography. The third was the 5-chamber view showing the aortic root. The fourth transverse view was slightly more cephalad and showed the right ventricular outflow tract, the main pulmonary artery, the bifurcation of the left and right pulmonary arteries, and cross-sections of the ascending and descending aorta. The final transverse view was the 3 vessels and trachea (3VT) plane showing the pulmonary trunk, proximal aorta, ductus arteriosus, distal aorta, superior vena cava, and trachea. 3) The fetus was scanned longitudinally along the spine to obtain the 3 long-axis views: the aortic arch, ductus arch section, and the longaxis view of the inferior and superior vena cava. 4) The probe was rotated $90^{\circ}$ around the long axis of the heart to obtain the other 2 short-axis views of the heart: the aortic root short-axis view and the biventricular short-axis view. 5) Open color Doppler was performed on a clear 2-dimensional image to check for signal consistent with abnormal blood flow. The flow spectrums of each valve orifice, the foramen ovale, and the ductus arteriosus were recorded using pulsed Doppler.

\section{Definition and classification methods}

Simple persistent left superior vena cava, isolated fetal arrhythmia, and other causes of heart dysfunction were excluded in accordance with Mitchell's definition (Mitchell et al., 
1971). In addition, hypertrophic cardiomyopathy and dilated cardiomyopathy are primary myocardial diseases and were thus not included as CHD (Hoffman and Kaplan, 2002).

In this study, hearts with $>1$ lesion were classified according to the most important lesion, and only one diagnosis was recorded for each case. This classification scheme will tend to underestimate the total frequency of common components of complex disease, such as pulmonary stenosis (PS), coarctation of the aorta (CoA), and VSD. Therefore, in order to ascertain the frequency of each cardiac structural defect, this study classified the cardiac defects of each case of CHD into 5 categories according to the location of the lesions in the fetal heart. These categories were: 1) ventricular malformations, referring to lesions of either ventricle and/or the ventricular septum and comprising VSD, single ventricle (SV), hypoplasia of left heart syndrome (HLHS), and hypoplasia of right heart syndrome (HRHS); 2) great artery anomalies, referring to lesions of the aorta and pulmonary artery and comprising persistent truncus arteriosus (PTA), PS, pulmonary atresia (PA), aortic stenosis (AS), CoA, double-outlet right ventricle (DORV), transposition of the great arteries (TGA), and interrupted aortic arch; 3) atrioventricular valve and endocardial cushion-related lesions, referring to lesions of the mitral and tricuspid valves and endocardial cushion and comprising atrioventricular septal defect (AVSD) and mitral or tricuspid atresia or stenosis; 4) atrial lesions, referring to lesions of the 2 atria and comprising single atrium (SA) and triatriatum; and 5) semilunar valve lesions, referring to lesions of the aortic and pulmonary valves.

In cases of unfavorable fetal position, the examination was repeated the same day or the following day. Autopsy was performed in cases of complex lesions in which the pregnancy was terminated. In cases of CHD in which the pregnancy resulted in a live birth, all newborn infants diagnosed prenatally with CHD were re-examined by neonatal echocardiography to confirm the diagnosis.

\section{RESULTS}

\section{Spectrum of CHD diagnosed using fetal echocardiography}

Among the 4370 pregnancies, 195 cases of CHD were diagnosed using fetal echocardiography, for a frequency of $4.5 \%$. Each specific type of CHD and the coexisting malforma-

tions are shown in Table 1 and Figure 1A. We were able to reassess the diagnosis of complex CHD in 44 cases, including 21 cases in which pregnancy was terminated and an autopsy performed and 23 cases in which the infant was examined postnatally by echocardiography. Among these 44 cases, the rate of coincidence of the prenatal echocardiographic diagnosis of fetal complex CHD and the autopsy or postnatal diagnosis was $100 \%$.

The 5 most-common types of CHD were, in order, SV (15.9\%, 31/195), AVSD (12.3\%, $24 / 195)$, VSD $(11.8 \%, 23 / 195)$, TOF $(10.8 \%, 21 / 195)$, and DORV $(8.2 \%, 16 / 195)$.

\section{Locations of cardiac structural defects}

A total of 316 defects were detected in the 195 cases of CHD. The most common lesions in the fetal heart with CHD by location were, in order, ventricular malformations $(40.5 \%, 128 / 316)$, great artery anomalies $(38.0 \%, 120 / 316)$, endocardial cushion abnormalities $(11.7 \%, 37 / 316)$, atrial abnormalities $(6.6 \%, 21 / 316)$, and semilunar valve abnormalities 
(3.2\%, 10/316) (Table 2 and Figure 1B). The most common components of complex fetal CHD lesions were, in order, VSD, PS/PA, and PTA.

\begin{tabular}{|c|c|c|}
\hline Type of CHD & $\mathrm{N}(\%)$ & Coexisting malformations \\
\hline SV & $31(15.9)$ & $\begin{array}{l}4 \text { cases associated with SA; } 7 \text { cases associated with PTA; } 9 \text { cases associated } \\
\text { with SA and PTA; } 5 \text { cases associated with PS; } 3 \text { cases associated with TGA; } \\
2 \text { cases associated with AVSD; } 1 \text { case associated with CoA }\end{array}$ \\
\hline AVSD & $24(12.3)$ & $\begin{array}{l}5 \text { cases associated with PTA; } 4 \text { cases associated with DROV; } \\
2 \text { cases associated with PS; } 1 \text { case associated with SA; } \\
1 \text { case associated with CoA }\end{array}$ \\
\hline VSD & $23(11.8)$ & \\
\hline TOF & $21(10.8)$ & \\
\hline DORV & $16(8.2)$ & $\begin{array}{l}5 \text { cases of Taussig-Bing syndrome; } 5 \text { cases associated with PS; } \\
3 \text { cases associated with interrupted aortic arch; } 2 \text { cases associated with AS }\end{array}$ \\
\hline HLHS & $14(7.2)$ & \\
\hline PTA & $11(5.6)$ & 6 cases associated with VSD; 1 case of mitral atresia; \\
\hline TGA & $10(5.1)$ & $\begin{array}{l}4 \text { cases of corrected TGA associated with VSD; } 3 \text { cases of complete TGA; } \\
1 \text { case associated with VSD; }\end{array}$ \\
\hline PS & $9(4.6)$ & 1 case associated with large ASD and VSD; \\
\hline Tricuspid atresia & $6(3.1)$ & $\begin{array}{l}1 \text { case associated with TGA; } 1 \text { case associated with DORV and interrupted; } \\
\text { aortic arch }\end{array}$ \\
\hline $\mathrm{CoA}$ & $6(3.1)$ & 3 cases associated with VSD; \\
\hline HRHS & $5(2.6)$ & \\
\hline SA & $4(2.1)$ & 1 case associated with VSD \\
\hline Ebstein anomaly & $4(2.1)$ & \\
\hline PA & $4(2.1)$ & 1 case associated with SA and PTA; \\
\hline AS & $4(2.1)$ & 1 case associated with VSD \\
\hline Triatriatum & $3(1.5)$ & \\
\hline
\end{tabular}

$\mathrm{CHD}=$ congenital heart disease; $\mathrm{SV}=$ single ventricle; $\mathrm{AVSD}=$ atrioventricular septal defect; VSD = ventricular septal defect; TOF = tetralogy of Fallot; DORV = double-outlet right ventricle; HLHS = hypoplasia of left heart syndrome; PTA = persistent truncus arteriosus; TGA = transposition of great arteries; PS = pulmonary stenosis; $\mathrm{ASD}=$ atrial septal defect; $\mathrm{CoA}=$ coarctation of the aorta; $\mathrm{HRHS}=$ hypoplasia of right heart syndrome; $\mathrm{SA}=$ single atrium; $\mathrm{PA}=$ pulmonary atresia; $\mathrm{AS}=$ aortic stenosis.
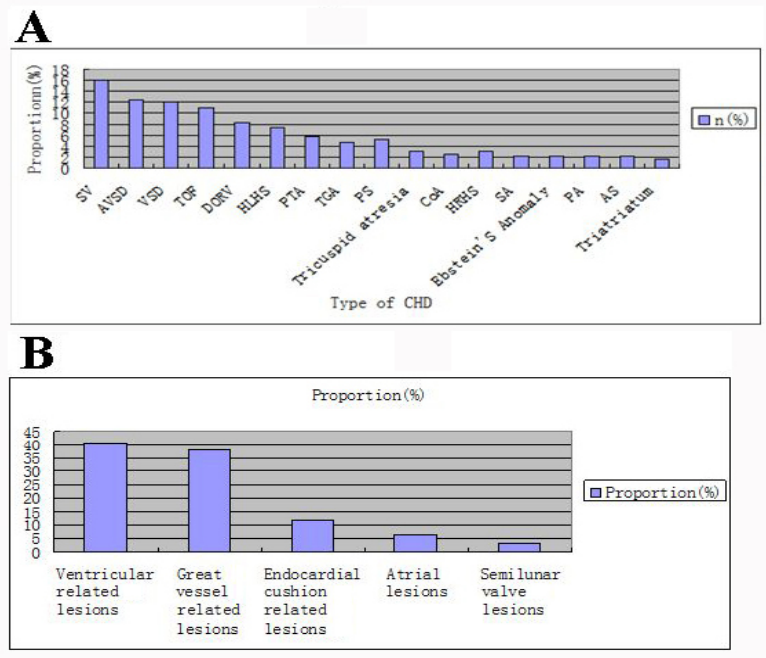

Figure 1. A. Distribution and proportions of the types of fetal CHD among the 195 cases. B. Distribution and proportions of the 316 cardiac lesions among the 195 cases of fetal CHD. 
Table 2. Frequency and distribution of the 316 cardiac lesions among the 195 cases of fetal CHD.

\begin{tabular}{lc}
\hline Type of lesion & Frequency (\%) \\
\hline Ventricular malformation & $128(40.5)$ \\
VSD & $77(24.4)$ \\
SV & $31(9.8)$ \\
HLHS & $14(4.4)$ \\
HRHS & $6(1.9)$ \\
Great artery anomaly & $120(38.0)$ \\
PTA & $33(10.4)$ \\
PS and PA & $42(13.3)$ \\
CoA & $7(2.2)$ \\
Interrupted aortic arch & $4(1.3)$ \\
TGA & $13(4.1)$ \\
DORV & $21(6.6)$ \\
Endocardial cushion-related lesion & $37(11.7)$ \\
Tricuspid atresia & $6(1.9)$ \\
Mitral atresia & $1(0.3)$ \\
Ebstein anomaly & $4(1.3)$ \\
AVSD & $26(8.2)$ \\
Atrial lesion & $21(6.6)$ \\
SA & $19(6.0)$ \\
Triatriatum & $3(0.9)$ \\
Semilunar valve lesion & $10(3.2)$ \\
AVS & $4(1.3)$ \\
PVS & $6(1.9)$ \\
\hline
\end{tabular}

${ }^{\mathrm{a} A s}$ a component of AVSD; VSD in AVSD was classified as an endocardial cushion-related lesion rather than a ventricular lesion. 'Includes defects in TOF. For other abbreviations, see legend to Table 1.

In this group, the total proportion of right-sided obstructive lesions, including TOF, PA, PS, HRHS, and tricuspid atresia, was much higher than that of left-sided obstructive lesions, including CoA, AS, HLHS, and mitral atresia [18.4\% (58/316) vs 9.5\% (30/316)].

\section{DISCUSSION}

In this study, the top 5 types of prenatally detected CHD were, in order, SV, AVSD, VSD, TOF, and DORV. SV was the most common type of CHD in this group, accounting for $16.1 \%$ of cases (31/195). The spectrum of prenatally detected CHD was completely different from that seen postnatally, in which simple types of CHD (VSD, ASD, PDA, etc.) were the most common. Complex defects were detected by fetal echocardiography much more often than were simple defects, possibly due to the high prenatal detection rate and large proportion of perinatal loss in cases of severe, complex cardiac anomalies. The technological advances and broader application of fetal echocardiography have allowed the prenatal diagnosis of all types of CHD by experienced practitioners (Allan and Sharland, 2001), greatly altering our understanding of the spectrum of fetal CHD. The sensitivity and specificity of fetal echocardiography for the diagnosis of complex CHD have been shown to be $94.4 \%$ and $99.8 \%$, respectively (Plesinac et al., 2007). A review by Germanakis and Sifakis (2006) encompassing 7 large-scale studies of fetal cardiac diagnosis indicated that an overall reduction of $15 \%$ between the prenatal and postnatal prevalence of CHD was expected and that the estimated impact of prenatal diagnosis on the prevalence of live-born CHD was greater for complex CHD, such as HLHS (almost 40\% reduction) and AVSD, SV, and TA (21-27\% reduction each), and less pronounced for the remaining types of $\mathrm{CHD}(<10 \%$ reduction). Fetuses with severe and complex CHD, especially if complicated by extracardiac malformations or chromosomal ab- 
normalities, have a low rate of survival after birth. Furthermore, selective pregnancy termination may be an option in cases of complex defects. Therefore, the true frequency of complex CHD during the fetal period may be much higher than estimates based on the prevalence among newborns or children.

We compared the top 5 types of prenatally detected CHD in this group with the findings of other authors from different geographical areas (Eronen, 1997; Tegnander et al., 2006; Yang et al., 2009), and the results are shown in Table 3. The series had some common characteristics: (1) complex defects were more common prenatally in all of the series; (2) despite differences in their rankings according to the frequency of detection, almost all of the series found AVSD among the 5 most common types of fetal CHD; and (3) VSD was the only simple CHD to appear among the 5 most common types of CHD in these prenatal series.

\begin{tabular}{|c|c|c|c|c|c|c|}
\hline \multirow[t]{2}{*}{ Authors } & \multirow[t]{2}{*}{ Location } & \multicolumn{5}{|c|}{ Spectrum and percentages of the top 5 types of CHD } \\
\hline & & 1 & 2 & 3 & 4 & 5 \\
\hline Allan et al. (1994) & London & $\begin{array}{l}\text { AVSD } \\
(17.6 \%)\end{array}$ & $\begin{array}{l}\text { HLHS } \\
(16.0 \%)\end{array}$ & $\begin{array}{l}\mathrm{CoA} \\
(11.2 \%)\end{array}$ & $\begin{array}{l}\text { Ebstein } \\
(7.5 \%)\end{array}$ & $\begin{array}{l}\text { VSD } \\
(6.0 \%)\end{array}$ \\
\hline Tegnander et al. (2006) & Norway & $\begin{array}{l}\text { AVSD } \\
(21.6 \%)\end{array}$ & $\begin{array}{l}\text { TGA } \\
(17.5)\end{array}$ & $\begin{array}{l}\text { HLHS } \\
(10.3 \%)\end{array}$ & $\begin{array}{l}\text { CoA } \\
(9.3 \%)\end{array}$ & $\begin{array}{l}\text { VSD } \\
(9.3 \%)\end{array}$ \\
\hline Eronen (1997) & Finland & $\begin{array}{l}\text { VSD } \\
(21.8 \%)\end{array}$ & $\begin{array}{l}\text { HLHS } \\
(20.0 \%)\end{array}$ & $\begin{array}{l}\text { AVSD } \\
(14.5 \%)\end{array}$ & $\begin{array}{l}\text { SV } \\
(12.7 \%)\end{array}$ & $\begin{array}{l}\text { DORV } \\
(5.5 \%)\end{array}$ \\
\hline Yang et al. (2009) & Beijing & $\begin{array}{l}\text { AVSD } \\
(15.9 \%)\end{array}$ & $\begin{array}{l}\text { VSD } \\
(15.2 \%)\end{array}$ & $\begin{array}{l}\text { TOF } \\
(13.2 \%)\end{array}$ & $\begin{array}{l}\text { SV/TGA/DORV } \\
(9.3 \%)\end{array}$ & $\begin{array}{l}\text { PS } \\
(5.3 \%)\end{array}$ \\
\hline Hsiao et al. (2007) & Taiwan & $\begin{array}{l}\text { Atrial isomerism } \\
(22.3 \%)\end{array}$ & $\begin{array}{l}\text { HLHS } \\
(11.6 \%)\end{array}$ & $\begin{array}{l}\text { TOF } \\
(10.7 \%)\end{array}$ & $\begin{array}{l}\text { DORV } \\
(10.7 \%)\end{array}$ & $\begin{array}{l}\mathrm{PS} / \mathrm{PA} \\
(6.8 \%)\end{array}$ \\
\hline Present study & China & $\begin{array}{l}\text { SV } \\
(15.9 \%)\end{array}$ & $\begin{array}{l}\text { AVSD } \\
(12.3 \%)\end{array}$ & $\begin{array}{l}\text { VSD } \\
(11.8 \%)\end{array}$ & $\begin{array}{l}\text { TOF } \\
(10.8 \%)\end{array}$ & $\begin{array}{l}\text { DORV } \\
(8.2 \%)\end{array}$ \\
\hline
\end{tabular}

For other abbreviations, see legend to Table 1.

In this study, the overall percentage of right-sided obstructive lesions, such as TOF, HRHS, PS, and PA, was much higher than that of left-sided obstructive lesions, such as CoA, AS, HLHS [(18.4\% (58/316) vs 9.5\% (30/316)]. The frequencies of CoA and HLHS, which were not among the top 5 types of CHD, were 2.5 and $7.2 \%$, in contrast with the much higher values reported in Western studies (9.3-11.2\% and $10.3-20.0 \%$, respectively), as shown in Table 3. Other previous studies have also suggested that Asian children have fewer left ventricular obstructive lesions and more right ventricular outflow tract lesions compared with Caucasian children (Jacobs et al., 2000). In a study from Hong Kong, the distribution of types of CHD among 666 children showed significantly more with critical PS and fewer with AS and HLHS (Sung et al., 1991). Another Asian study found frequencies of CoA and AS only approximately one-fourth to one-fifth of those in Western reports (Lue, 1988). These findings were also confirmed by results from Taiwan, California, and elsewhere (Pradat et al., 2003; Wu et al., 2010). The present study found that Chinese fetuses are more likely to have right-sided obstructive lesions and less likely to have left-sided obstructive lesions, but the reasons for this are not clear. Differences in genetic origin and race may provide a possible explanation.

The present study also found a significant preponderance of ventricular malformations rather than great artery anomalies and endocardial cushion defects. Atrial and semilunar valve lesions were less commonly detected by fetal echocardiography (shown in Table 2). This might result from embryonic cardiac development, which needs to be further studied. 
On the other hand, the overall percentage of ventricular malformations $(40.5 \%)$ and atrial lesions $(6.6 \%)$ was $47.1 \%$, which coincided exactly with the percentage of CHD that can be diagnosed from the 4-chamber view of the fetus. Previous studies have shown that about 30$50 \%$ of fetal CHD, generally the ventricular malformations such as SV, HLHS, HRHS, and AVSD, can be detected in the 4-chamber view of the fetus (Bull, 1999; Wong et al., 2003). Addition of the ventricular outflow tract view and the 3-vessel view allows the diagnosis of great artery abnormalities and increases the detection rate to 70-90\% (Carvalho et al., 2002; Sklansky et al., 2009). This rate was consistent with the total percentage of ventricular malformations, atrial lesions, and great artery anomalies in the present study (85.1\%). Therefore, the combined use of different fetal echocardiography views is valuable for the diagnosis of CHD, especially complex CHD with multiple malformations of different parts of the heart. The present study also showed that although simple VSD was not the most common type of fetal CHD, it was the most common component of complex defects and accounted for $24.3 \%$ of the total number of CHD lesions, as shown in Table 2. Knowing the relative frequencies of the different lesions may aid our diagnostic process by prompting us to consider common lesions before rarer lesions. For epidemiologists, the frequencies of various lesions may help to understand their causes.

In summary, the spectrum of fetal CHD detected by echocardiography differed greatly from past assumptions. Prenatally, complex defects were more common than simple defects. Ventricular malformations accounted for the largest part of all CHD lesions, and VSD was the most common component of complex defects. Chinese fetal CHD comprised more right-sided obstructive lesions than left-sided obstructive lesions. Reliable information about the common types of CHD is important because it may lead to better insight into their etiologies.

The present study does have certain limitations. The study was conducted in high-risk pregnancies retrospectively, and the sample size was fairly small; in addition, a considerable number of cases lost to follow-up, and the quantity of follow-up data in the remaining cases was limited owing to cultural and religious reasons. An accurate picture of the true prevalence of CHD will require a large prospective study of a series of pregnancies representative of the entire population. However, the current simplicity and accuracy of fetal echocardiography makes this by no means impossible.

\section{ACKNOWLEDGMENTS} (\#08H10).

Research supported by Shaanxi Provincial Health Department research projects

\section{REFERENCES}

Allan LD and Sharland GK (2001). The echocardiographic diagnosis of totally anomalous pulmonary venous connection in the fetus. Heart 85: 433-437.

Allan LD, Crawford DC, Anderson RH and Tynan M (1985). Spectrum of congenital heart disease detected echocardiographically in prenatal life. Br. Heart J. 54: 523-526.

Allan LD, Sharland GK, Milburn A, Lockhart SM, et al. (1994). Prospective diagnosis of 1006 consecutive cases of congenital heart disease in the fetus. J. Am. Coll. Cardiol. 23: 1452-1458.

Bull C (1999). Current and potential impact of fetal diagnosis on prevalence and spectrum of serious congenital heart disease at term in the UK. British Paediatric Cardiac Association. Lancet 354: 1242-1247.

Carvalho JS, Mavrides E, Shinebourne EA, Campbell S, et al. (2002). Improving the effectiveness of routine prenatal 
screening for major congenital heart defects. Heart 88: 387-391.

Eronen M (1997). Outcome of fetuses with heart disease diagnosed in utero. Arch. Dis. Child Fetal Neonatal Ed. 77: F41-F46.

Germanakis I and Sifakis S (2006). The impact of fetal echocardiography on the prevalence of liveborn congenital heart disease. Pediatr. Cardiol. 27: 465-472.

Hoffman JI and Kaplan S (2002). The incidence of congenital heart disease. J. Am. Coll. Cardiol. 39: 1890-1900.

Hsiao SM, Wu MH, Jou HJ, Lee CN, et al. (2007). Outcome for fetuses with prenatally detected congenital heart disease and cardiac arrhythmias in Taiwan. J. Formos. Med. Assoc. 106: 423-431.

Jacobs EG, Leung MP and Karlberg J (2000). Distribution of symptomatic congenital heart disease in Hong Kong. Pediatr. Cardiol. 21: 148-157.

Lue HC (1988). Congenital heart disease in the East and West. Acta Paediatr. Sin. (Suppl B) 39-45B.

Mitchell SC, Korones SB and Berendes HW (1971). Congenital heart disease in 56,109 births. Incidence and natural history. Circulation 43: 323-332.

Plesinac S, Terzic M, Stimec B and Plecas D (2007). Value of fetal echocardiography in diagnosis of congenital heart disease in a Serbian university hospital. Int. J. Fertil. Womens Med. 52: 89-92.

Pradat P, Francannet C, Harris JA and Robert E (2003). The epidemiology of cardiovascular defects, part I: a study based on data from three large registries of congenital malformations. Pediatr. Cardiol. 24: 195-221.

Sklansky MS, Berman DP, Pruetz JD and Chang RK (2009). Prenatal screening for major congenital heart disease: superiority of outflow tracts over the 4-chamber view. J. Ultrasound Med. 28: 889-899.

Sung RY, So LY, Ng HK, Ho JK, et al. (1991). Echocardiography as a tool for determining the incidence of congenital heart disease in newborn babies: a pilot study in Hong Kong. Int. J. Cardiol. 30: 43-47.

Tegnander E, Williams W, Johansen OJ, Blaas HG, et al. (2006). Prenatal detection of heart defects in a non-selected population of 30,149 fetuses - detection rates and outcome. Ultrasound Obstet. Gynecol. 27: 252-265.

van der Linde D, Konings EE, Slager MA, Witsenburg M, et al. (2011). Birth prevalence of congenital heart disease worldwide: a systematic review and meta-analysis. J. Am. Coll. Cardiol. 58: 2241-2247.

Wong SF, Chan FY, Cincotta RB, Lee-Tannock A, et al. (2003). Factors influencing the prenatal detection of structural congenital heart diseases. Ultrasound Obstet. Gynecol. 21: 19-25.

Wu MH, Chen HC, Lu CW, Wang JK, et al. (2010). Prevalence of congenital heart disease at live birth in Taiwan. $J$. Pediatr. 156: 782-785.

Yagel S, Cohen SM and Achiron R (2001). Examination of the fetal heart by five short axis views: a proposed screening method for comprehensive cardiac evaluation. Ultrasound Obstet. Gynecol. 17: 367-369.

Yang XY, Li XF, Lü XD and Liu YL (2009). Incidence of congenital heart disease in Beijing, China. Chin. Med. J. (Engl.) 122: $1128-1132$. 